\title{
Electrically Conductive Membranes Obtained by Simultaneous Electrospinning and Electrospraying Processes
}

\author{
Martina Roso, Alessandra Lorenzetti, Carlo Boaretti, and Michele Modesti \\ Department of Industrial Engineering, University of Padova, Via Marzolo 9, Padova, Italy \\ Correspondence should be addressed to Martina Roso; martina.roso@unipd.it
}

Received 9 May 2016; Accepted 30 October 2016

Academic Editor: Miguel A. Correa-Duarte

Copyright ( 2016 Martina Roso et al. This is an open access article distributed under the Creative Commons Attribution License, which permits unrestricted use, distribution, and reproduction in any medium, provided the original work is properly cited.

\begin{abstract}
Electrically conductive polyurethane nanostructured membranes have been prepared combining the electrospinning of polymer nanofibers (NFs) with the electrospraying of pristine multiwall carbon nanotubes (MWCNTs) in simultaneous processes. In order to have a better understanding of the distribution of MWCNTs on the surface of the membranes, the optimization of the electrospraying process has been carried out and the distribution of MWCNTs has been evaluated using image texture analysis techniques. Large membranes with a volume resistivity typical of electrostatic discharge materials with a MWCNTs concentration less than $0.3 \%$ wt $\left(0.01 \mathrm{mg} / \mathrm{cm}^{2}\right)$ have been obtained and characterized with morphological (SEM and TEM) and spectroscopic (UV-Vis, Raman) techniques.
\end{abstract}

\section{Introduction}

In many industrial dust collection systems, the filtration and electrical properties of the filter media play an important role in the performance and safety of the system. During processing, electric charges can develop. If the filter media cannot minimize and dissipate the charges, there is a chance for their accumulation and eventually the electrostatic discharge (ESD) can occur, leading to explosions, fires, or personal injury from shock.

Electrostatic charge occurs in fluid systems as a result of friction between the fluid and system components, including filters. Charges generated by the filter can collect on the filter element building up extremely high voltages in the order of tens of thousands of volts. Many methods have been investigated to prevent charging and the damage that can occur if the electrostatic discharge continues unchecked. One preventative safety measure to reduce external discharge is the use of grounded filter housings and pipelines; however this method does not stop either fluid charge generation or internal damage to the filter or other system components caused by sparking. Another method, adding antistatic additive to the liquid, is restricted only to fuel applications. Other approaches are surface modification of the filter media or incorporating conducting materials into the construction of the filter element. These methods can eliminate direct damage to the filter cartridges as a hinder of charge accumulation and potential sparking: the production of a nanostructured membrane with the aforementioned properties represents the aim of this research [1].

Membranes composed of polymeric fibers of nanoscale diameter are acquiring increasingly importance in many research areas due to their peculiar properties. Nanofibers exhibit better mechanical performance and more flexibility than fibers of larger diameter. Though, the very large specific surface area makes these structures suitable for a wide range of applications.

One of the most economic and versatile methods for nonwoven nanofibers production, which has gained a growing interest in the scientific community within the last decade, is electrospinning. The application of an electric tension to a polymeric solution involves charges generation within the solution itself and a subsequent emission of an electrified jet is achieved when the electrostatic charges overcome the surface tension. Upon solvent evaporation and stretching of the jet, nonwoven nanofibers are collected on the support [2]. Several parameters, such as environmental and operating conditions, 
as well as the solution properties, can affect the final morpho$\log y$ and the related properties. However, thanks to the wide experience gained during the last ten years of extensive research, it is possible to predict, for example, the pore size distribution of electrospun membranes by theoretical modelling $[3,4]$. As regards their applications, filtration [2-6], technical and protective clothing industry [7], biomedical scaffolding [8], sensors $[9,10]$, and functionalized membranes [11-13] are just few examples of the wide range of implementation fields of the nanofibers.

A further step in nanofibers technology has been the realization of nanocomposites with surprising structural and functional properties. Nanostructured systems of polymeric fibers reinforced with ceramic and metallic nanoparticles are widely experimented in the field of catalytic filtration [14], sensing devices, and bone tissue regeneration too.

What, nowadays, draws the attention of experts is the use of carbon nanotubes (CNTs) in nanocomposite technology due to their exceptional mechanical and electrical characteristics, low density, and high aspect ratio.

Nanocomposite nanofibers, charged with carbon nanotubes, can be obtained via electrospinning of a polymer/CNTs solution (or melt) [15-17]. A very fine dispersion of MWCNTs is essential to reach a percolation threshold at very low content, thus making the fibers conduct electrical current. While in bulk composites the percolation condition, depending on matrix properties, occurs with nanotubes concentrations of about $1-5 \%$, in nanofibers this value should be definitely lower due to the monodimensionality of such systems. However, while nanotubes are embedded in the polymer, conduction between different fibers is limited by matrix insulating properties: just exposed nanotubes can exchange electrical charge with the surroundings.

CNTs coated nanofibers exhibit higher electric conductivity and the stability of the system is granted by hydrophobic interactions between nanotubes sides and polymer chains [18]. Deep coating, possibly sonication enhanced [19], is an easy approach to produce such systems. MWCNTs, suspended in a surfactant/water solution, have better affinity with polymer chains rather than with the solvent and are quickly absorbed by the membrane. This method seems to be strongly influenced by the properties (hydrophilicity, porosity, NF dimensions, etc.) of the specific processed membrane which affect the possibility to prior control the amount of MWCNTs that will be absorbed. In order to increase the stability of interaction between nanotubes and nanofibers, electro-hydro-dynamic atomization (EHD) processes or more simply electrospraying could represent a valid approach to this purpose and it has been already explored just in a few papers in the literature: for instance, Shi et al. [18] proposed branch-like carboxylated MWCNTs (f-MWCNTs)/Chitosan (CS) nanofibrous membranes for dye removal. Even though bulk system based nanotubes-polymer composites have been widely studied and reported in scientific literature, very few works report about nanostructured hybrid membranes, often describing data that are unlikely to be reproduced [20-22].

Electrically conductive membranes with a reasonable control of the charge amount can be easily prepared through the electrospray of a MWCNTs suspension over the electrospun fibers. The nanotube dose is regulated by deposition time and flow rate of the suspension. In this work we propose a detailed study of a process for the production of nanofiber mats with an electrically conductive behaviour due to the introduction of carbon nanotubes. The electrospraying process for nanotubes deposition has been extensively investigated since no detailed works about the effect of the process parameters have been found in the scientific literature.

\section{Experimental}

2.1. Membrane Preparation. A commercial thermoplastic polyurethane (Elastollan B $60 \mathrm{D}$ from BASF) with elastomeric properties was used as polymeric matrix. The polymer, dissolved in N,N-dimethylformamide (20 wt\%), was electrospun from a syringe unsharpened needle $(0.4 \mathrm{~mm}-27 \mathrm{G})$ at the rate of $1.0 \mathrm{~mL} / \mathrm{h}$ with an applied electric potential of $18 \mathrm{kV}$ and positioned at $200 \mathrm{~mm}$ from the collector.

Membranes have been prepared on a rotating drum (diameter $=80 \mathrm{~mm}$; length $=300 \mathrm{~mm}$ ) controlled by an inverter Omron V1000 with a rotation speed that can be varied between 100 and 5000 rpms; minimum speed was set to avoid preferential orientation of deposited fibers.

Moreover this method requires the use of two syringe pumps (NE300 from New Era Pump Systems, Inc.) for polymer solution and MWCNTs suspension. Two voltage generators (ES60P-20W from Gamma High Voltage Research) have been used in order to optimize the process parameters for both depositions. A closed chamber and a thermohygrometer to control environmental parameters completed the equipment.

Multiwalled carbon nanotubes (MWCNTs) from Nanocyl (NC7000), which are produced via the catalytic carbon vapor deposition (CCVD) process using a specific catalyst of $\mathrm{Fe}(0.4 \%)$ and $\mathrm{Co}(0.2 \%)$ supported on $\mathrm{Al}_{2} \mathrm{O}_{3}$ nanoparticles (97.6\%), have been used. They have low diameter (about $10 \mathrm{~nm})$ and high aspect ratio (>150) with a specific area of about $250-300 \mathrm{~m}^{2} / \mathrm{g}$ according to producer data.

Pristine MWCNTs were dispersed in water and sodium dodecyl sulfate (SDS) $(0.5 \mathrm{wt} \%)$ at the concentration of $0.25 \mathrm{wt} \%$ under tip sonication (1 hour, $200 \mathrm{~W}$ ) in thermostatic bath at $0^{\circ} \mathrm{C}$. After centrifugation at $4800 \mathrm{rpms}$ for $1 \mathrm{~h}$ the suspension was still stable without having produced a measurable precipitate, and this has allowed the use of those suspensions for several experiments.

Developing the simultaneous approach, three different arrangements of NFs and MWCNTs emitters have been tested, incident $\left(<10^{\circ}\right)$, orthogonal $\left(90^{\circ}\right)$, and antiparallel $\left(180^{\circ}\right)$, as shown in Figure 1.

The processing conditions adopted for all the approaches are reported in Table 1.

\subsection{Electrospraying Optimization and Image Analysis. Poly-} meric electrospun membranes are widely studied systems and optimum deposition conditions can be found for most polyurethane compounds and in many previous works [23]. Thus, our efforts were focused on the study and the optimization of 
TABLE 1: Processing conditions for both electrospinning of TPU and electrospraying of MWCNTs.

\begin{tabular}{|c|c|c|c|c|c|c|c|c|}
\hline Sample & & $\begin{array}{c}\text { Applied voltage } \\
\mathrm{kV}\end{array}$ & $\begin{array}{c}\text { Flow rate } \\
\mathrm{mL} / \mathrm{h}\end{array}$ & $\begin{array}{c}\text { Needle diameter } \\
\mathrm{mm}\end{array}$ & $\begin{array}{l}\text { Distance tip-collector } \\
\mathrm{cm}\end{array}$ & $\begin{array}{l}\mathrm{T} \\
{ }^{\circ} \mathrm{C} \\
\end{array}$ & $\begin{array}{c}\mathrm{RH} \\
\%\end{array}$ & $\begin{array}{c}\text { Time } \\
\mathrm{h}\end{array}$ \\
\hline \multirow{2}{*}{ Incident } & TPU & 18 & 0.5 & 0.4 & 20 & \multirow{2}{*}{24} & \multirow{2}{*}{60} & \multirow{2}{*}{3} \\
\hline & MWCNTs & 18 & 1 & 0.4 & 10 & & & \\
\hline \multirow{2}{*}{ Orthogonal } & TPU & 18 & 0.5 & 0.4 & 20 & \multirow{2}{*}{24} & \multirow{2}{*}{60} & \multirow{2}{*}{3} \\
\hline & MWCNTs & 18 & 1 & 0.4 & 10 & & & \\
\hline \multirow{2}{*}{ Antiparallel } & TPU & 12 & 1 & 0.4 & 20 & \multirow{2}{*}{24} & \multirow{2}{*}{63} & \multirow{2}{*}{3} \\
\hline & MWCNTs & 18 & 1 & 0.4 & 10 & & & \\
\hline
\end{tabular}

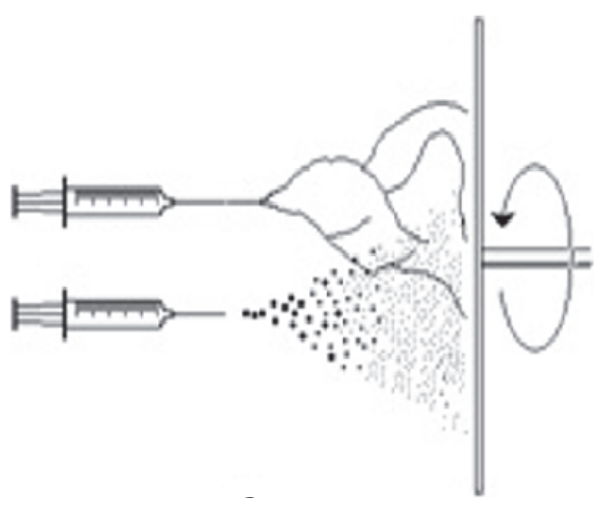

(a)

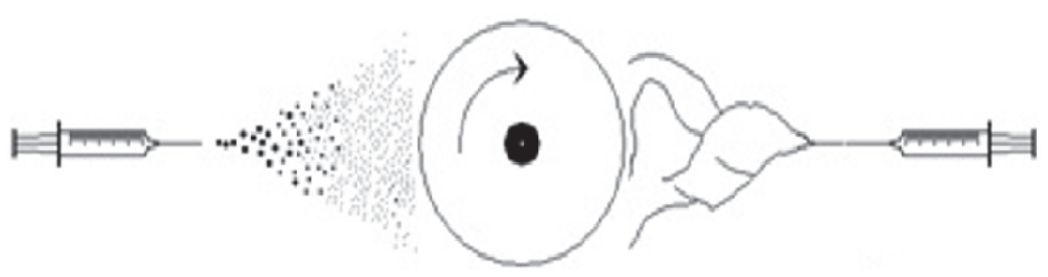

(c)

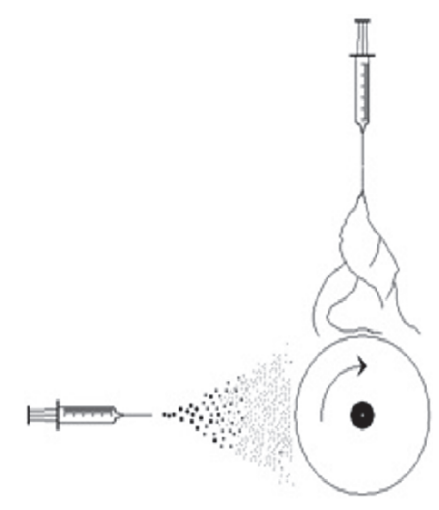

(b)

FIGURE 1: Electrospinning/electrospraying configurations.

TABLE 2: Parameters levels considered for process optimization.

\begin{tabular}{lccc}
\hline Variable & Level 1 & Level 2 & Level 3 \\
\hline Applied voltage & $10 \mathrm{kV}$ & $15 \mathrm{kV}$ & $18 \mathrm{kV}$ \\
Flow rate & $2 \mathrm{~mL} / \mathrm{h}$ & $1 \mathrm{~mL} / \mathrm{h}$ & $0.5 \mathrm{~mL} / \mathrm{h}$ \\
Needle diameter & $20 \mathrm{G}$ & $22 \mathrm{G}$ & $27 \mathrm{G}$ \\
\hline
\end{tabular}

carbon nanotubes electrospraying process in order to obtain a tiny and even deposition.

Experimental parameters were investigated depositing a known amount of MWCNTs suspension $(0.167 \mathrm{~mL}$ of a $0.25 \mathrm{wt} \%$ suspension) on a paper sheet mounted on a drum and varying needle diameter, applied voltage, and flow rate. All the variables levels are reported in Table 2.

The goal of this approach is the choice of parameters that permit us to obtain an even dark background of single MWCNTs with a minimal presence of small macroscopic drops.
The electrospray process produced on sheets a distribution of macroscopic drops on an even grey background due to the deposition of well-dispersed MWCNTs.

Paper sheets, with deposited MWCNTs drops have been digitalized with a high resolution scanner at $1200 \mathrm{dpi}$ and grey tones without any compression. A ruler, previously printed on sheets, has been used to calibrate images' scale. A square portion $10 \mathrm{~cm}$ wide has been extracted from the central area of each image and processed through the Fiji image analyser software. Each pixel in images corresponds to an area of about $(20 * 20) \mu \mathrm{m}^{2}$ and the colour intensity is correlated with the amount of carbon nanotubes deposited in there. With the "Histogram" function it had been possible to graph the colour intensity distribution and evaluate the threshold between the background and the drops. The peak at higher colour values (lighter grey tones) is related to background contribution and the "mode" has been taken as an estimate of average background level. A proper threshold function has been implemented to calculate the fraction of the area covered by drops. 
Because we were interested in background information, images have been processed with the "Subtract Background" utility that permit to calculate the background contribution and to save it as a new picture.

The plot of profiles (vertical averaging) of whole images, of related backgrounds, and of the calculated drops contributions was used to compare electrospray quality of deposition.

2.3. Characterization. Electric properties of membrane have been evaluated through the 8009 Resistivity Text Fixture of the Keythley 6517b Electrometer, specifically designed to measure high resistivity material films. The probe has an annular electrode of the diameter of $55 \mathrm{~mm}$ and can measure both surface and bulk resistivity. Measures were taken after 60 s of electrification time and repeated 15 times alternating the applied potential to avoid charge accumulation.

For lower resistivity materials, a four-contacts probe has been used to test local electric properties in combination with a Keythley 2000 Multimeter. The probe, specifically realized, is provided with piston-like electrodes, with spherical head $(r=0.52 \mathrm{~mm})$ to minimize the penetration in the membrane; the interelectrode distance is $10 \mathrm{~mm}$.

The amount of carbon nanotubes deposited on membranes has been measured through spectroscopic method. A membrane portion $\left(25 \mathrm{~cm}^{2}\right)$ from the central homogeneous region has been dissolved in a xylene/DMF 1:1 emulsion to a polymer nominal concentration of $1 \mathrm{mg} / \mathrm{mL}$. Solutions have been analysed with a Lambda $25 \mathrm{UV}-\mathrm{Vis}$ Spectrometer (Perkin Elmer Instruments) between 500 and $800 \mathrm{~nm}$. The tail of the strong nanotubes absorption peak $(280 \mathrm{~nm})$ has been measured at $700 \mathrm{~nm}$ and related to the absorption coefficient calculated after calibration with samples of known MWCNTs concentration (1, 5, and $10 \mathrm{mg} / \mathrm{L})$ [24]. Wavelength of $700 \mathrm{~nm}$ has been chosen because calibration measures have best agreement, with their mean, near that value.

Extent of the interaction between MWCNT and nanofibers has been investigated trying to redisperse nanotubes from a membrane to a SDS/water solution (1-2\% w/w) through tip sonication at the same conditions of dispersions preparation (200 W, 1 hour, $0^{\circ} \mathrm{C}$ ).

Scanning electron microscopy, SEM (JSM-6490, JEOL Ltd., Japan), and transmission electron microscopy, TEM (FEI Tecnai G12, $100 \mathrm{KV}$ with TVIPS TietzF114 photocamera) were used for morphological analysis. Sample preparation for TEM imaging has been carried out as follows: the membrane samples were embedded in a proper epoxy resin and slices of $100 \mathrm{~nm}$ thickness were obtained by ultramicrotomy of the cured resin. TEM analysis of the electrosprayed solutions was carried out by deposition of a small drop of suspension on the cupper grid commonly used as sample holder.

The surface chemistry of the materials in terms of crystal structure has been explored by Raman spectroscopy (Micro Raman DRX, Thermofisher) using a laser excitation wavelength of $532 \mathrm{~nm}$ and $0.5 \mathrm{~mW}$ laser to preserve sample from damaging or laser induced heating, using 100x objective.

\section{Results and Discussion}

3.1. Electrospraying Optimization and Image Analysis. The tricky step during the whole process was to achieve a uniform distribution of nanoparticles over the nanofiber surface. Because of this, our first technological objective dealt with electrospraying of MWCNTs to gain a better understanding of the process and the effect of suspension parameters on the nanocluster distribution and uniformity. A first optical evaluation of the parameters effect has been depicted from the analysis of the digitalized images shown in Figure 2 obtained with the $27 \mathrm{G}$ needle (for the sake of brevity, the images obtained for other needles sizes are reported in Figures S1 and S2 in the Supporting Information in Supplementary Material available online at http://dx.doi.org/10.1155/2016/8362535). As it can be observed, the increase of voltage, all the other conditions being equal, generally resulted in more uniform deposition of MCNTs spread over the collector surface. This can be ascribed to the higher charge density of the suspension, with a consequent lower stability of the electrified jet and higher frequency of jet fragmentation. As regards the flow rate, its effect could not be generalized because it is strongly related to the voltage. For every applied voltage there is a fixed dragging rate which moves the forming-bead toward the collector. When the feed rate of suspension is higher, an excess of electrostatic charges will be cumulated in the solution at the tip of the needle resulting on whipping motion and jet splaying and consequently these instabilities enhance beads diameter reduction. This statement found confirmation in the run experiments at low voltage, showing that a decrease in the flow rate not always results in the best beads dimensions and distribution.

Looking at the needle size effect, the lower was the inner diameter of the needle, the lower was the diameter of the beads, and a more homogeneous distribution could be achieved. The lower the needle diameter is, that is, the lower the electrified jet diameter is, the higher its charge density is, all the other conditions being equal. This means that it could reach the bending instability and jet fragmentation faster, resulting in finer particles generation.

In order to get a more objective analysis of the parameters effects, according to the aforementioned procedure, the optimization of electrospraying was carried out through image analysis of MWCNTs drops. Figure 3 shows the plot of profiles for different operating conditions; from this analysis the best operating conditions, at which the contribution of the resulting drops to the total profile was minimized, were pointed out.

According to the obtained results, electrospraying parameters have been set to $18 \mathrm{kV}$ of applied voltage and $1.0 \mathrm{~mL} / \mathrm{h}$ of flow rate, using the $0.4 \mathrm{~mm}$ needle $(27 \mathrm{G})$.

3.2. Membrane Characterization. Before going into details of the membrane characterization, it is necessary to spend some words about the effect of the specific configuration adopted for membrane production, that is, the incident, orthogonal, and antiparallel. The incident approach, in which emission cones are almost completely overlapped, brought a strong interaction between forming nanofibers and MWCNTs 


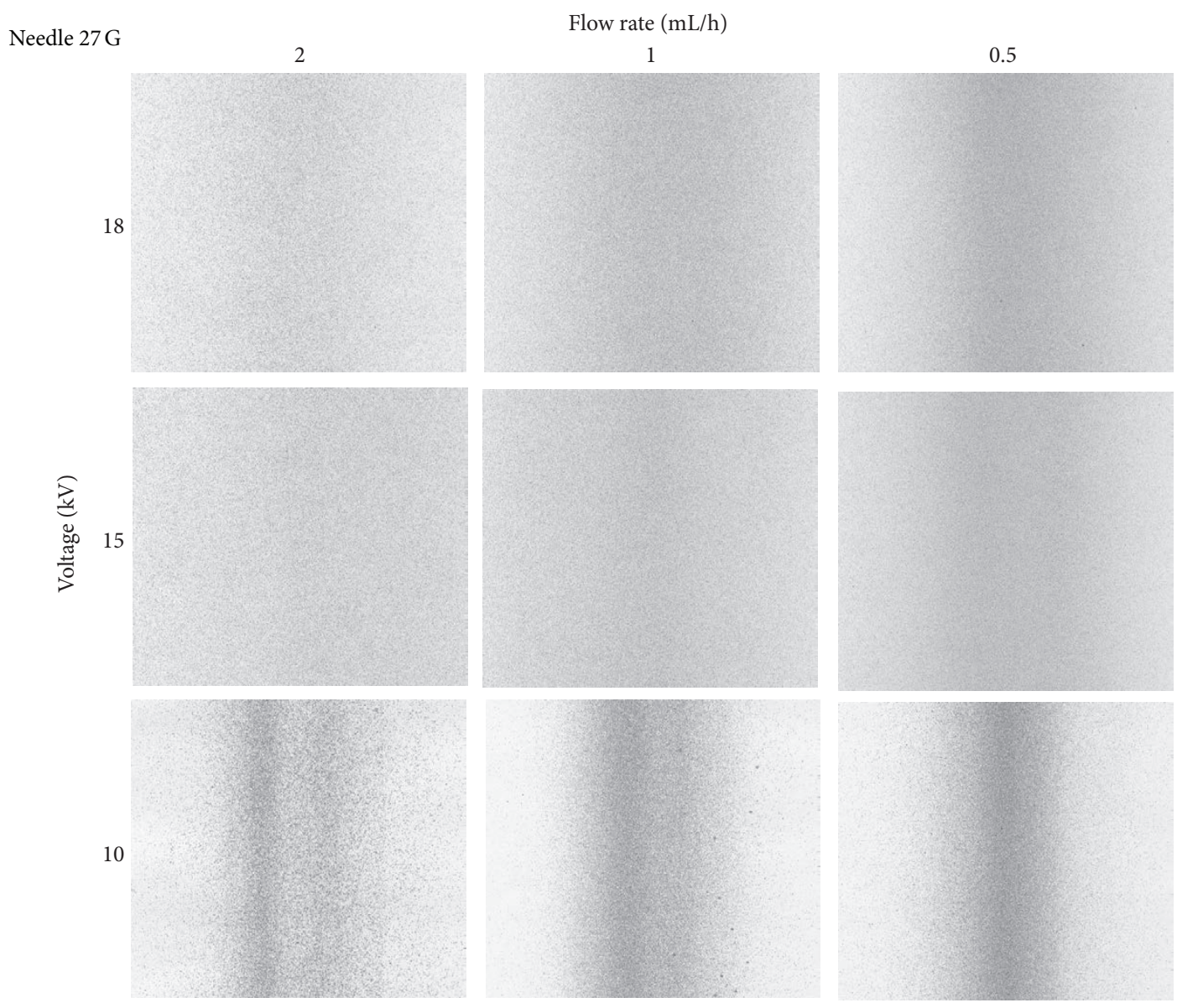

Figure 2: Images of the obtained samples at different electrospraying conditions, with $27 \mathrm{G}$ needle.

which are both positively charged. The reciprocal repulsion is likely to make polymer and nanotubes to deposit in different region of the drum forming completely uneven membranes decorated with very large drops. The orthogonal arrangement provides again a partial overlap of the spray cone with the nanofiber jet near the deposition region and leads to the same, even if minor, problem.

In the last arrangement, where the MWCNTs and polymer sources are positioned at the opposite sides of the drum, the interaction between material jets is minimized.

3.2.1. Determination of MWCNTs Concentration. Individual MWCNTs are active in the UV-Vis region and exhibit characteristic bands corresponding to additional absorption due to $1 \mathrm{D}$ van Hove singularities [24]. According to the literature [24], the absorbance of MWCNTs solutions showed a maximum between 200 and $300 \mathrm{~nm}$ and gradually decreases from UV to near-IR, which is partly due to scattering, especially in the lower wavelength range. However, the solvents used for this analysis, that is, xylene and DMF, had a cut-off wavelengths $\left(\lambda_{\mathrm{CO}}\right)$ at $325 \mathrm{~nm}$ and $300 \mathrm{~nm}$ [25], respectively, and their signals overlapped the adsorption peak of nanotubes. Only water $\left(\lambda_{\mathrm{CO}}=190 \mathrm{~nm}\right)$ and acetonitrile $\left(\lambda_{\mathrm{CO}}=200 \mathrm{~nm}\right)$ would be the proper solvents to carry out such characterization, but the polymer was not soluble in them. The blank used was both a $1 \mathrm{mg} / \mathrm{mL}$ TPU solution (Xylene/DMF 1: 1) solution and a $10 \mathrm{mg} / \mathrm{L}$ SDS solution in the same solvents. Neither of two showed absorption in the wavelength range 450-800 nm (see Figure S3, Supporting Information) and their contribution was assumed to be negligible. Since it was not possible to evaluate the absorption at $260 \mathrm{~nm}$, the acquisitions of all the samples have been done in the UV-Vis region, from 300 to $700 \mathrm{~nm}$, and the absorbance at $700 \mathrm{~nm}$ has been used for calibration.

According to the aforementioned calibration, at fixed concentrations (Figure 4) of MWCNTs, the consistence of the measured signal by Lambert-Beer equation has been verified, calculating the extinction coefficient $\varepsilon_{\mathrm{MWCNTS}}$ :

$$
\varepsilon_{\mathrm{MWCNTs}}=\frac{A}{[\mathrm{MWCNTs}] * b}[\mathrm{~L} /(\mathrm{cm} * \mathrm{mg})],
$$

where $A$ is the absorbance (a.u.), [MWCNTs] is the concentration of MWCNTs in the solution in $[\mathrm{mg} / \mathrm{L}]$, and $b$ is the path length of the beam of light through the material sample in $[\mathrm{cm}]$. Figure 4 illustrates UV-Vis spectra of MWCNTs solutions, obtained in the same conditions. The relationship between the absorption coefficient and the wavelength is reported in Figure 5, wherein a mean value of $\varepsilon_{\text {MWCNTs }}=$ $0.0436 \mathrm{~L} /(\mathrm{cm} * \mathrm{mg})$ was depicted from the calibration curves. The application of (1) for the solutions obtained from the 

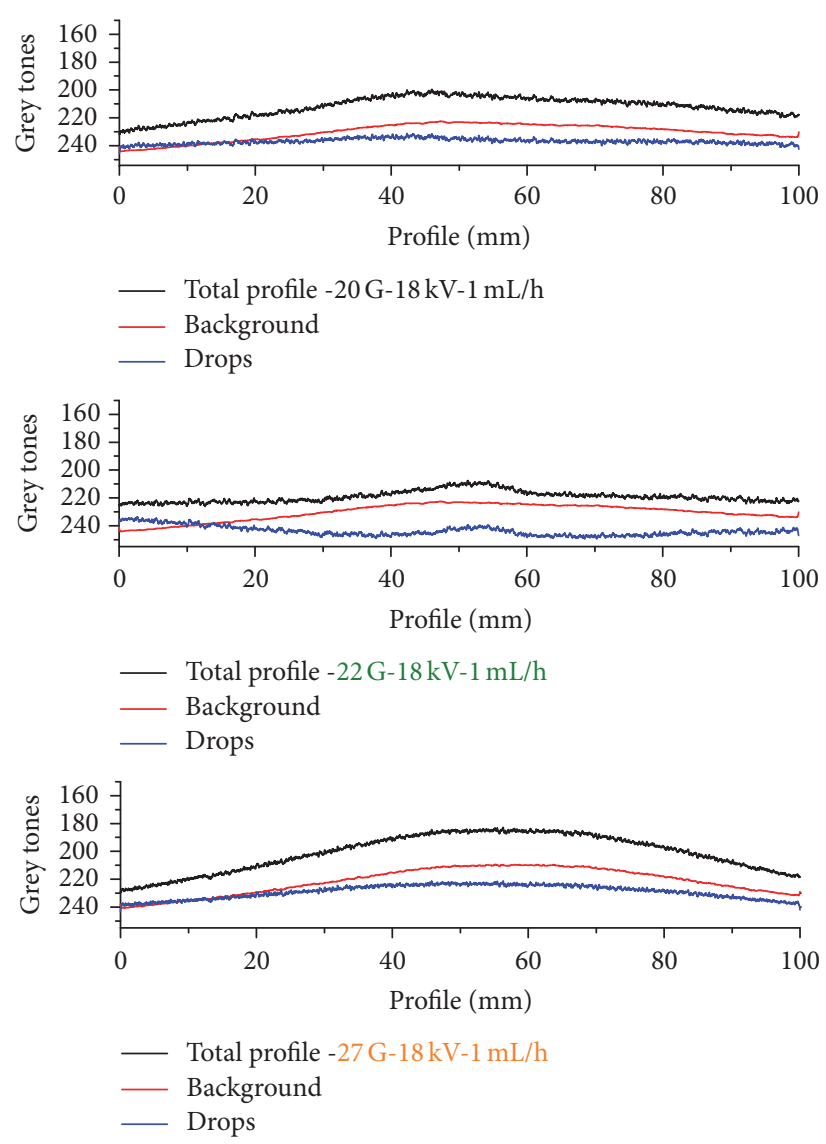

FIGURE 3: Plot of profiles (vertical averaging) of different conditions with related backgrounds and drops contributions.

TABLE 3: MWCNTs concentration of the obtained samples.

\begin{tabular}{lcc}
\hline Sample & Mean [MWCNTs] wt\% & Mean [MWCNTs] $\mathrm{mg} / \mathrm{cm}^{2}$ \\
\hline Incident & 0.05 & 0.002 \\
Orthogonal & 0.4 & 0.016 \\
Antiparallel & 0.3 & 0.012 \\
\hline
\end{tabular}

produced membranes resulted in the determination of the MWCNTs concentration for all the tested configurations and the results of the mean values are shown in Table 3. As it can be observed, the membranes obtained by incident approach reported a very low mean concentration because of the nonuniform deposition of the MWCNTs.

3.2.2. Morphological Characterization. With the experimental settings reported in Experimental, 80 to $100 \mathrm{~mm}$ wide nanofiber mats were produced. Depending on environmental conditions, TPU fibers with a diameter in the range of 0.1$10 \mu \mathrm{m}$ were obtained.

All the produced membranes were characterized by SEM analysis in order to have a better understanding of the morphology as a function of the process configurations. As regards the membrane obtained by incident arrangement, because of the nonhomogeneous MWCNTs distribution obtained on these membranes (see Figure S4, Supporting

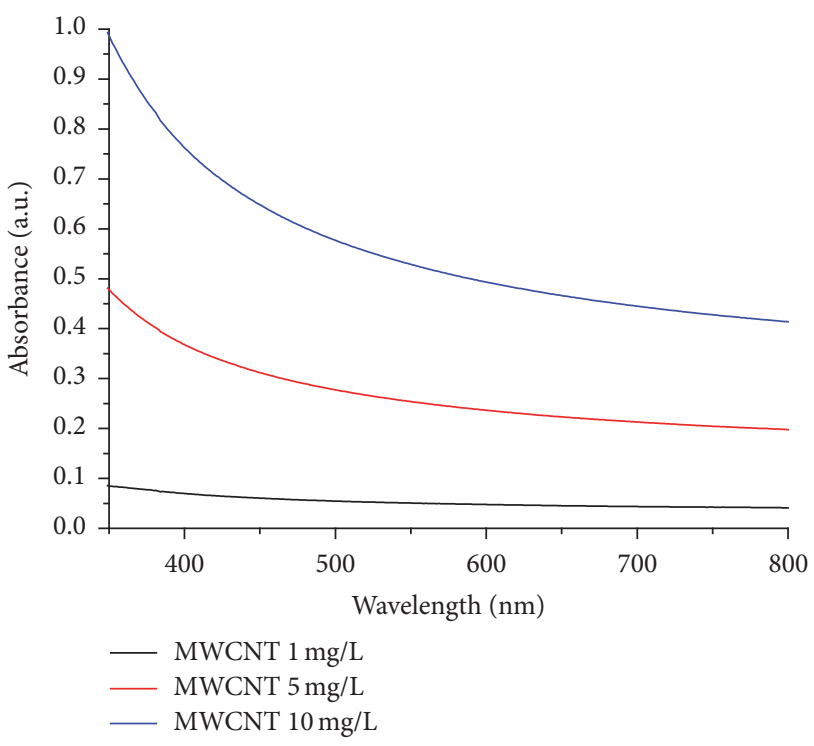

FIgURE 4: Absorbance calibration curves.

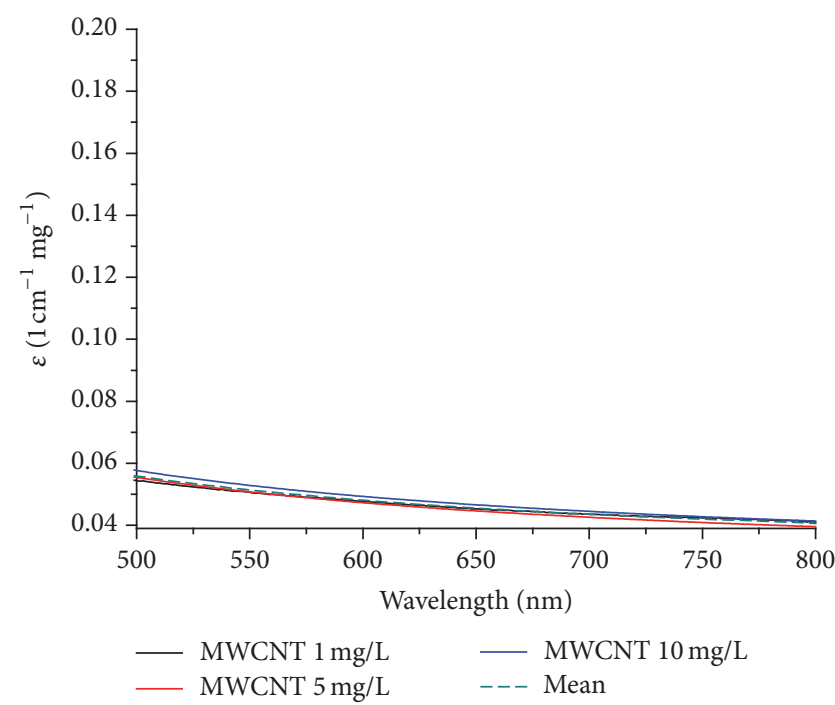

FIGURE 5: Extinction coefficient versus wavelength for the calibration solutions.

Information), it has been decided not to consider this configuration for further analysis. The micrographs of the neat TPU membrane as well as membrane obtained by antiparallel configuration are reported in Figure 6.

As it can be observed, the pristine TPU electrospun membrane exhibited smooth and beads-free surfaces without branch-like structures whereas the simultaneous electrospinning and spraying resulted in branch-like structures. The possible formation of such branch-like structures can be understood by considering that, upon solvent evaporation, TPU nanofibers solidified on the collector and the MWCNTs, which travel in the same way, are subjected to electrostatic adsorption over the surface. This morphology was the same for both the orthogonal and antiparallel approaches (for the sake of brevity, SEM micrograph of orthogonal configuration 


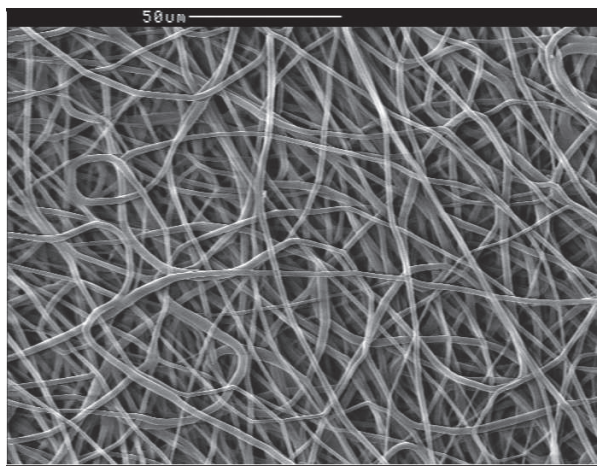

(a)

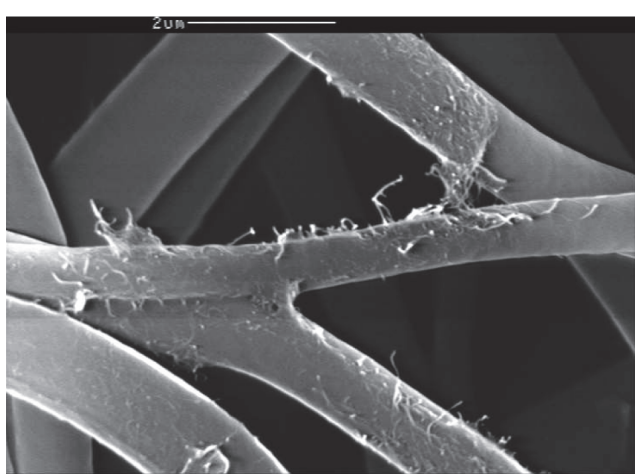

(b)

FIGURE 6: SEM micrographs of (a) pure TPU electrospun mat and (b) TPU-MWCNTs membranes by antiparallel configuration.

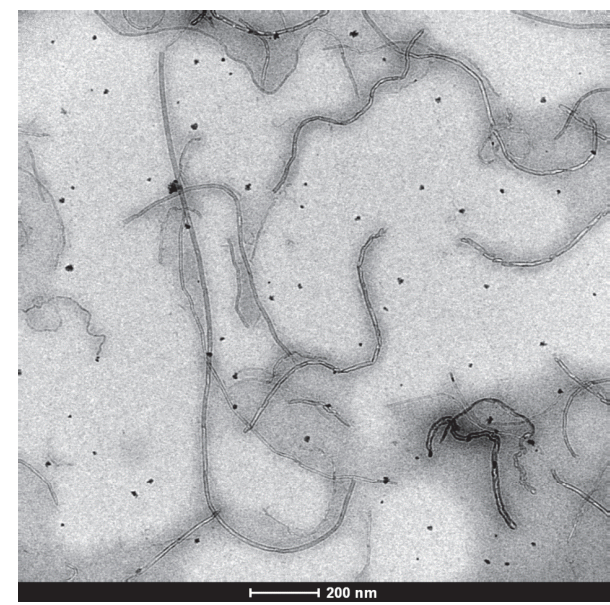

(a)

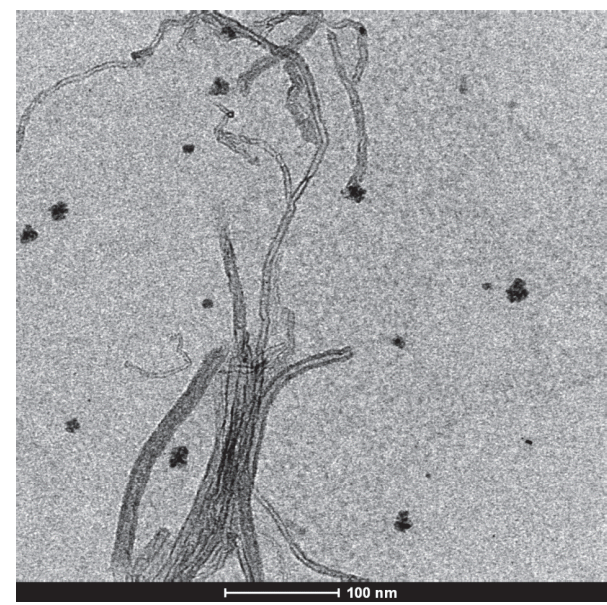

(b)

FIGURE 7: TEM micrographs of MWCNTs from suspension.

was not shown here). Single MWCNTs, characterized by a well-visible hollow internal channel, have been reported in the TEM micrographs of the MWCNTs suspensions (Figure 7). Looking at TPU/MWCNTs membrane obtained by antiparallel configuration (Figure 8), the MWCNTs are clearly visible among the fibers as well as the elliptic shapes which represent the sections of electrospun TPU nanofibers. At higher magnification (Figure 8(b)), it was possible to appreciate single nanotubes bearing at the tip, rarely at an intermediate length position, a Ni particle having a size roughly equal to that of the internal diameter of the associated carbon nanotubes.

Further interesting details can be depicted from Figure 9. Thanks to the simultaneous approach, it was evident that the nanotubes were able to create a network among the fibers ensuring a complete connection in the whole membrane. From the electrical point of view, this could be very important and the electrical properties that confirmed this statement are reported hereinafter.

3.2.3. Raman Spectroscopy. In order to ensure that sonication did not damage and cut MWCNTs, Raman spectra of both the pristine nanotubes NC7000 and the sonicated suspension (CNT Sonic) were acquired and they are reported in Figure 10. As it can be observed, the mains D band $\left(1345 \mathrm{~cm}^{-1}\right)$ and $\mathrm{G}$ band $\left(1587 \mathrm{~cm}^{-1}\right)$ did not show any variation of both frequency and relative intensity, meaning that the sonication has not damaged the nanotubes.

At $2700 \mathrm{~cm}^{-1}$, a lower relative intensity for the MWCNTs Sonic sample could be identified as the overtone D band.

In the region of $500 \mathrm{~cm}^{-1}$ Raman shift, it was possible to see a variation in the structure of the transitions RBM (Radial Breathing Mode). These resonances are usually visible only in the single wall nanotubes, because in the MWCNTs these signals are subjected to a shielding effect due to the outer layers [26]. However, these signals were also been reported for the double wall nanotubes and for the MWCNTs with low diameter, because they are generated by the inner core tubes. Usually it is very difficult to appreciate these transitions due to the relation between the shift of the signal and the nanotube diameter. Consequently, the presence of such signals can be ascribed to both the quality of the nanotubes and the effective dispersing method that was adopted [26]. 


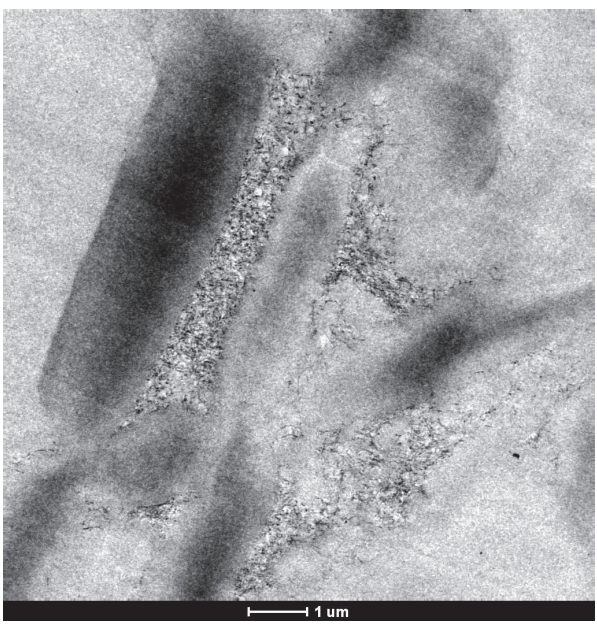

(a)

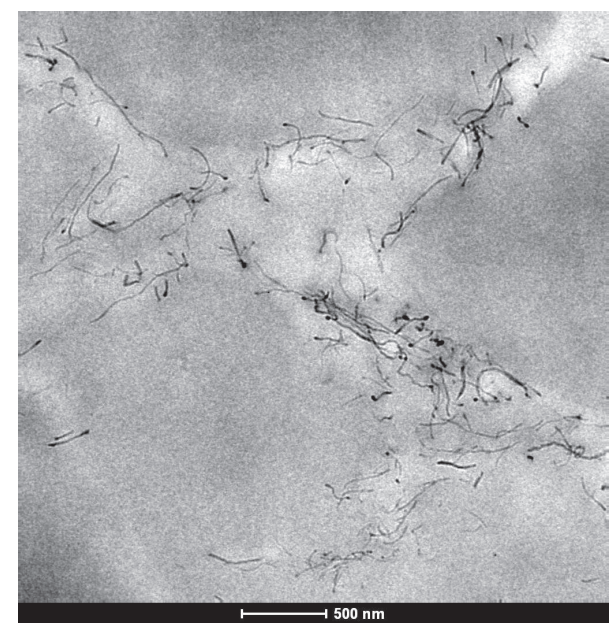

(b)

FIGURE 8: (a) TEM micrographs of the TPU/MWCNTs antiparallel deposition: (b) higher mag of the interfibers portion.

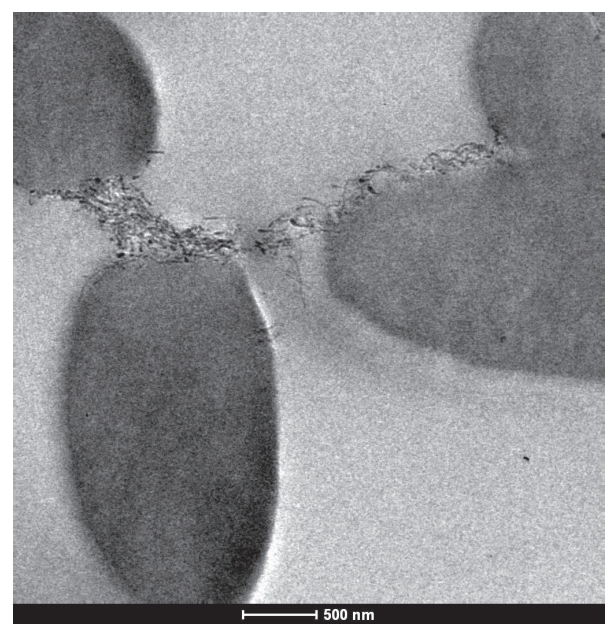

FIGURE 9: TEM micrograph of TPU/MWCNTs antiparallel configuration.

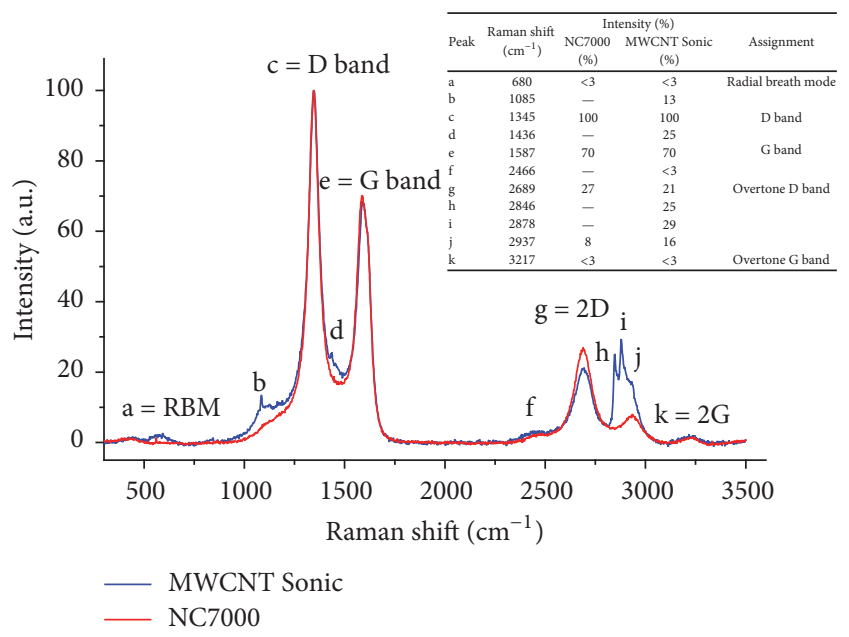

FIGURE 10: Raman spectra of carbon nanotubes and carbon nanotubes sonicated suspension.

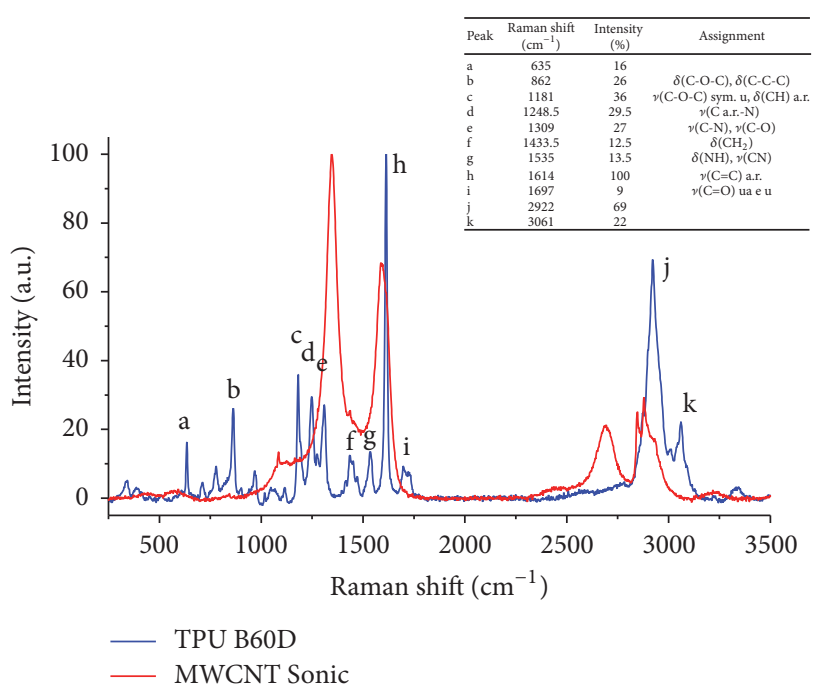

FIGURE 11: Raman spectra of electrospun TPU mat and MWCNTs suspension. $\mathrm{u}=$ urethane, $\mathrm{ua}=$ urea, a.r. $=$ aromatic ring, $\mathrm{w}$ : weak, $v$ : stretching mode, and $\delta$ : bending mode.

The signals which cannot be related to the nanotubes and that were reported only in the sonicated samples (b, d, $h$, and i) were conferred upon the presence of sodium dodecyl sulfate as surfactant. In fact, the resonance peaks (h) and (i) recorded at $2900 \mathrm{~cm}^{-1}$ are related to $\mathrm{C}-\mathrm{H}$ and $\nu(\mathrm{C}-\mathrm{H})$ stretching modes [27]. As regards the membranes, Figure 11 shows the Raman spectrum of the electrospun TPU mat in comparison with the sonicated MWCNTs suspension one. According to its complex molecular structure, tentative band assignments were made with reference to earlier Raman studies of polyurethanes [28-31] and are reported in Figure 11. Raman scattering intensity at $862 \mathrm{~cm}^{-1}$, related to the C-O-C and C$\mathrm{C}-\mathrm{C}$ bending, was used as a reference for normalization of all the spectra. 


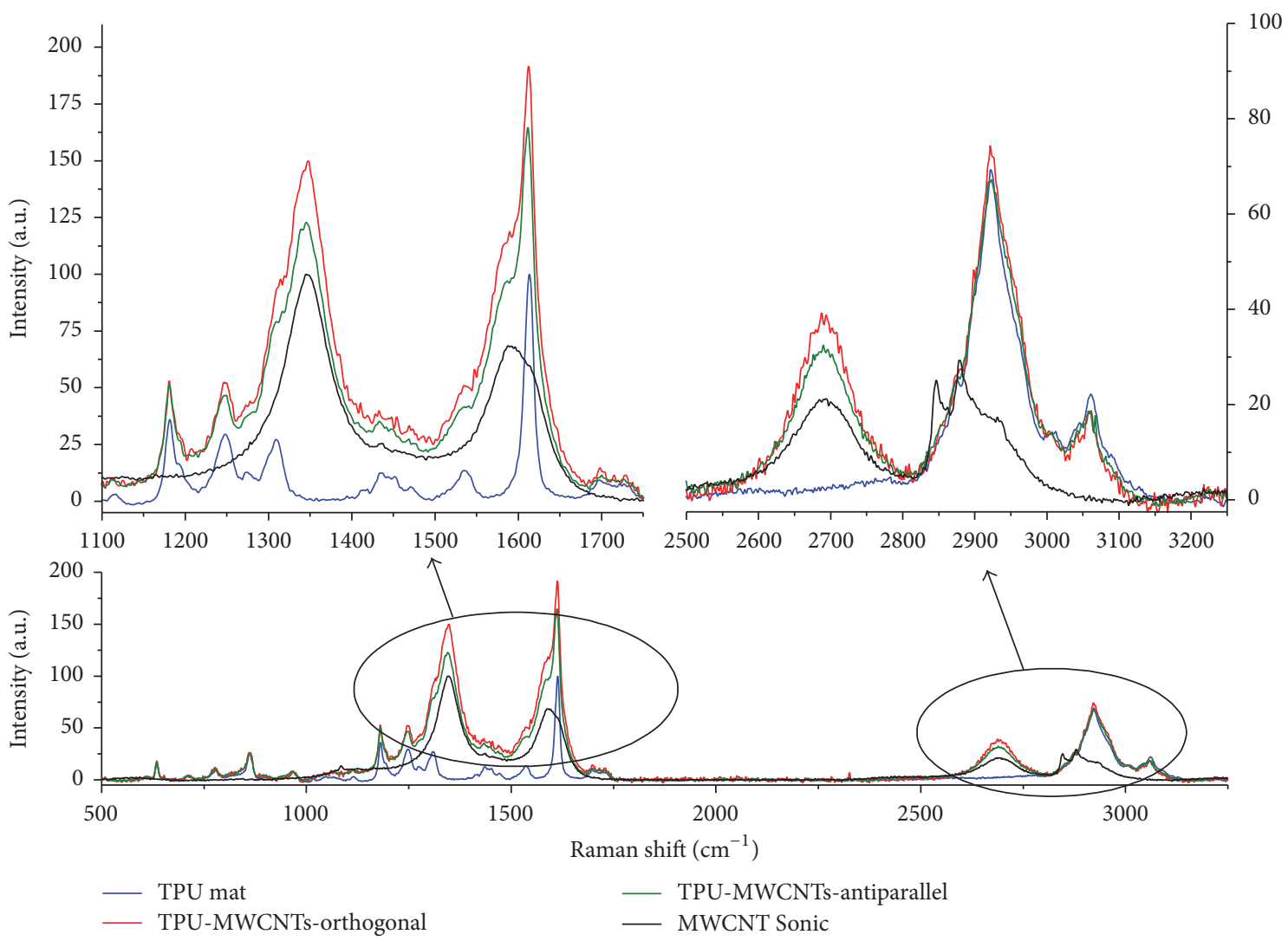

FIGURE 12: Raman spectra of the membranes produced in different configurations.

Raman spectra of the obtained membranes with both orthogonal and antiparallel configurations are reported in Figure 12. The Raman spectra that contained both the signals of MWCNTs and polymeric matrix were almost the same for both the arrangements, being the slight different intensity probably due to the different content in MWCNTs of the membranes.

3.3. Electrical Properties. Volume resistivity $(\mathrm{Ohm} * \mathrm{~cm})$ was measured for both the neat TPU and TPU/MWCNTs electrospun membranes (Table 4). For TPU-MWCNTs membranes the measurements were carried out on both sides of the membranes (Side 1 and Side 2).

According to the nature of the polymer itself, the results for neat TPU confirmed the insulating properties of the material. For electrically conductive membranes, a good agreement between the values calculated on both sides has been showed and this proved that the production process could be suitable and versatile for the production of filter elements with a good electrostatic discharge activity. The TPU/ MWCNTs antiparallel configuration showed the best performance in terms volume resistivity, that is, $7.88 E+05(\Omega \cdot \mathrm{cm})$, although very good results are obtained also for orthogonal approach. Moreover it has been shown that the resistivity is still low even when doubling the membranes thickness. Therefore, we can state that the approach here proposed is suitable to obtain an electrically conductive membrane with a very low content of MWCNTs and that the membranes are homogenous through the thickness.

3.4. Stability Test. MWCNTs interaction with other materials is mainly led by weak intermolecular forces. However, according to the high surface area of the polymeric electrospun mat, the interaction sites among MWCNTs and nanofibers could be very high in number, resulting in a stable and strong interaction between those materials. On the fiber surface, the sodium sulfate group (from SDS dispersant that was used for promoting and stabilizing the CTNs dispersion) could also react with the residual polar groups $\mathrm{N}-\mathrm{H}$ e $\mathrm{C}=\mathrm{O}$ of the polymer. The specific energy of dipole interaction should also be multiplied by the number of SDS molecules involved. Consequently, the intermolecular forces, both dipole-dipole and Van Der Waals interactions, could result in a strong and stable adhesion of the nanotubes on the electrospun fibers.

Extent of the interaction between MWCNTs and nanofibers has been investigated by measuring volume resistivity before and after the immersion and sonication of the membranes in SDS/water solution. The test has demonstrated that the stability of the MWCNTs coating on polyurethane nanofibers makes those systems suitable for practical applications, even in wet environments. In fact, the results in terms of volume resistivity showed in Table 5 for antiparallel sample revealed a $4 \%$ variation of the volume resistivity before and 
TABLE 4: Resistivity measurements of TPU/MWCNTs membranes obtained with different configurations.

\begin{tabular}{|c|c|c|c|c|c|c|c|}
\hline Thickness $(\mu \mathrm{m})$ & $54 \pm 6$ & \multicolumn{2}{|c|}{$50 \pm 6$} & \multicolumn{2}{|c|}{$53 \pm 5$} & \multicolumn{2}{|c|}{$101 \pm 10$} \\
\hline Configuration & Neat TPU & \multicolumn{2}{|c|}{ Orthogonal } & \multicolumn{2}{|c|}{ Antiparallel } & \multicolumn{2}{|c|}{ Antiparallel } \\
\hline \multirow{2}{*}{ Resistivity } & \multirow{2}{*}{ Volume $(\Omega \cdot \mathrm{cm})$} & \multicolumn{2}{|c|}{ Volume $(\Omega \cdot \mathrm{cm})$} & \multicolumn{2}{|c|}{ Volume $(\Omega \cdot \mathrm{cm})$} & \multicolumn{2}{|c|}{ Volume $(\Omega \cdot \mathrm{cm})$} \\
\hline & & Side 1 & Side 2 & Side 1 & Side 2 & Side 1 & Side 2 \\
\hline Max & $1.68 E+14$ & $3.96 E+06$ & $3.68 E+06$ & $8.53 E+05$ & $7.89 E+05$ & $9.09 E+05$ & $5.94 E+05$ \\
\hline Min & $1.64 E+14$ & $3.60 E+06$ & $3.41 E+06$ & $8.40 E+05$ & $7.84 E+05$ & $9.01 E+05$ & $5.76 E+05$ \\
\hline$\langle\rho\rangle$ & $1.66 E+14$ & $3.80 E+06$ & $3.54 E+06$ & $8.46 E+05$ & $7.88 E+05$ & $9.50 E+05$ & $5.83 E+05$ \\
\hline Std. dev. & $9.90 E+11$ & $1.10 E+03$ & $8.90 E+03$ & $3.99 E+03$ & $1.90 E+03$ & $2.60 E+03$ & $5.70 E+03$ \\
\hline
\end{tabular}

TABLE 5: Volume resistivity measurements before and after immersion and sonication in SDS/water solution.

\begin{tabular}{lcccc}
\hline & \multicolumn{4}{c}{ Volume resistivity $(\Omega \cdot \mathrm{cm})$} \\
& Min & $\operatorname{Max}$ & $\langle\rho\rangle$ & Std. dev. \\
\hline Before & $7.89 E+05$ & $7.84 E+05$ & $7.88 \mathrm{E}+05$ & $1.90 E+03$ \\
After & $8.21 E+05$ & $8.17 E+05$ & $8.19 \mathrm{E}+05$ & $2.00 E+03$ \\
\hline
\end{tabular}

after treatment, meaning a good interaction between the MWCNTs and the nanofibers and a negligible leaching effect.

\section{Conclusions}

In this study nanostructured membranes based on electrospun TPU fibers and electrosprayed MWCNTs were produced and characterized in two different conformations: the simultaneous orthogonal approach and the simultaneous antiparallel approach. Before membrane production, the electrospraying of MWCNTs has been optimized in order to evaluate the parameters effects on the quality of nanotubes deposition. Thanks to image texture analysis techniques, the best operating conditions have been selected to get a uniform deposition and fine beads dimensions. After production, TEM characterization of the membranes revealed that a nanotubes network has been created within the whole membrane and this network was responsible for the good electric properties of the nanostructured membrane. The volume resistivity moved from $1.7 E+14(\Omega \cdot \mathrm{cm})$ for the neat electrospun TPU to $3.6 E+6$ and $7.9 E+5(\Omega \cdot \mathrm{cm})$ for the orthogonal and antiparallel configurations, respectively, with a mean MWCNTs content ranging from 0.01 to $0.02 \mathrm{mg} / \mathrm{cm}^{2}$. These promising results make the proposed membrane a good candidate for preventing charging in filter media.

\section{Competing Interests}

The authors declare that they have no competing interests.

\section{References}

[1] J. K. Duchowski, L. Bensch, B. Phair, M. Khazan, and V. Tsalyuk, "Overcoming electrostatic discharge in hydraulic and lubricating applications by incorporating a novel filter media," in Proceedings of the STLE Annual Meeting, Las Vegas, Nev, USA, May 2016.
[2] M. Roso, C. Boaretti, A. Lorenzetti, and M. Modesti, "Electrospun nanofibrous membranes," in Encyclopedia of Membranes, E. Drioli and L. Giorno, Eds., pp. 1-5, Springer, Berlin, Germany, 2016.

[3] R. Bagherzadeh, S. S. Najar, M. Latifi, M. A. Tehran, and L. Kong, "A theoretical analysis and prediction of pore size and pore size distribution in electrospun multilayer nanofibrous materials," Journal of Biomedical Materials Research Part A, vol. 101, no. 7, pp. 2107-2117, 2013.

[4] R. Bagherzadeh, M. Latifi, and L. Kong, "Three-dimensional pore structure analysis of polycaprolactone nano-microfibrous scaffolds using theoretical and experimental approaches," Journal of Biomedical Materials Research Part A, vol. 102, no. 3, pp. 903-910, 2014.

[5] R. S. Barhate, C. K. Loong, and S. Ramakrishna, "Preparation and characterization of nanofibrous filtering media," Journal of Membrane Science, vol. 283, no. 1-2, pp. 209-218, 2006.

[6] R. Gopal, S. Kaur, Z. Ma, C. Chan, S. Ramakrishna, and T. Matsuura, "Electrospun nanofibrous filtration membrane," Journal of Membrane Science, vol. 281, no. 1-2, pp. 581-586, 2006.

[7] R. Knizek, D. Karhankova, and V. Bajzik, "Protective clothing using nanofibers," Advanced Materials Research, vol. 909, pp. 24-26, 2014.

[8] R. Danesin, P. Brun, M. Roso et al., "Self-assembling peptideenriched electrospun polycaprolactone scaffolds promote the h-osteoblast adhesion and modulate differentiation-associated gene expression," Bone, vol. 51, no. 5, pp. 851-859, 2012.

[9] F. Cao, S. Guo, H. Ma, D. Shan, S. Yang, and J. Gong, "Nickel oxide microfibers immobilized onto electrode by electrospinning and calcination for nonenzymatic glucose sensor and effect of calcination temperature on the performance," Biosensors and Bioelectronics, vol. 26, no. 5, pp. 2756-2760, 2011.

[10] Y. Ding, Y. Wang, L. Su, M. Bellagamba, H. Zhang, and Y. Lei, "Electrospun $\mathrm{Co}_{3} \mathrm{O}_{4}$ nanofibers for sensitive and selective glucose detection," Biosensors and Bioelectronics, vol. 26, no. 2, pp. $542-548,2010$.

[11] D. Noreña-Caro and M. Álvarez-Láinez, "Functionalization of polyacrylonitrile nanofibers with $\beta$-cyclodextrin for the capture of formaldehyde," Materials \& Design, vol. 95, pp. 632-640, 2016.

[12] M. Mokhtari and A. R. Keshtkar, "Removal of Th(IV), Ni(II) and $\mathrm{Fe}(\mathrm{II})$ from aqueous solutions by a novel $\mathrm{PAN}-\mathrm{TiO}_{2}$ nanofiber adsorbent modified with aminopropyltriethoxysilane," Research on Chemical Intermediates, vol. 42, no. 5, pp. 40554076, 2016.

[13] S. R. Zahabi, S. A. H. Ravandi, and A. Allafchian, "Removal of nickel and cadmium heavy metals using nanofiber membranes functionalized with (3-mercaptopropyl)trimethoxysilane 
(TMPTMS)," Journal of Water and Health, vol. 14, no. 4, pp. 630639, 2016.

[14] M. Roso, A. Lorenzetti, C. Boaretti, D. Hrelja, and M. Modesti, "Graphene $/ \mathrm{TiO}_{2}$ based photo-catalysts on nanostructured membranes as a potential active filter media for methanol gasphase degradation," Applied Catalysis B: Environmental, vol. 176-177, pp. 225-232, 2015.

[15] J. H. Sung, H. S. Kim, H.-J. Jin, H. J. Choi, and I.-J. Chin, "Nanofibrous membranes prepared by multiwalled carbon nanotube/poly(methyl methacrylate) composites," Macromolecules, vol. 37, no. 26, pp. 9899-9902, 2004.

[16] Z. M. Mahdieh, V. Mottaghitalab, N. Piri, and A. K. Haghi, "Conductive chitosan/multi walled carbon nanotubes electrospun nanofiber feasibility," Korean Journal of Chemical Engineering, vol. 29, no. 1, pp. 111-119, 2012.

[17] F. Mei, J. Zhong, X. Yang et al., "Improved biological characteristics of poly(L-lactic acid) electrospun membrane by incorporation of multiwalled carbon nanotubes/hydroxyapatite nanoparticles," Biomacromolecules, vol. 8, no. 12, pp. 3729-3735, 2007.

[18] J. Shi, T. Wu, K. Teng et al., "Simultaneous electrospinning and spraying toward branch-like nanofibrous membranes functionalised with carboxylated MWCNTs for dye removal," Materials Letters, vol. 166, pp. 26-29, 2016.

[19] H. J. Yoo, H. H. Kim, J. W. Cho, and Y. H. Kim, "Surface morphology and electrical properties of polyurethane nanofiber webs spray-coated with carbon nanotubes," Surface and Interface Analysis, vol. 44, no. 4, pp. 405-411, 2012.

[20] D. Kimmer, P. Slobodian, D. Petras, M. Zatloukal, R. Olejník, and P. Sáha, "Polyurethane/multiwalled carbon nanotube nanowebs prepared by an electrospinning process," Journal of Applied Polymer Science, vol. 111, no. 6, pp. 2711-2714, 2009.

[21] M. T. Hunley, P. Pötschke, and T. E. Long, "Melt dispersion and electrospinning of non-functionalized multiwalled carbon nanotubes in thermoplastic polyurethane," Macromolecular Rapid Communications, vol. 30, no. 24, pp. 2102-2106, 2009.

[22] Q. Meng and J. Hu, "Self-organizing alignment of carbon nanotube in shape memory segmented fiber prepared by in situ polymerization and melt spinning," Composites Part A: Applied Science and Manufacturing, vol. 39, no. 2, pp. 314-321, 2008.

[23] M. Dasdemir, M. Topalbekiroglu, and A. Demir, "Electrospinning of thermoplastic polyurethane microfibers and nanofibers from polymer solution and melt," Journal of Applied Polymer Science, vol. 127, no. 3, pp. 1901-1908, 2013.

[24] J. Yu, N. Grossiord, C. E. Koning, and J. Loos, "Controlling the dispersion of multi-wall carbon nanotubes in aqueous surfactant solution," Carbon, vol. 45, no. 3, pp. 618-623, 2007.

[25] Kaye and Laby, Tables of Physical \& Chemical Constants, 16th edition, \$3.8.7 UV-Visible Spectroscopy, 1995.

[26] M. S. Dresselhaus, G. Dresselhaus, R. Saito, and A. Jorio, "Raman spectroscopy of carbon nanotubes," Physics Reports, vol. 409, no. 2, pp. 47-99, 2005.

[27] A. R. Paschoal, A. P. Ayala, R. C. F. Pinto et al., "About the SDS inclusion in PDMS/TEOS ORMOSIL: a vibrational spectroscopy and confocal Raman scattering study," Journal of Raman Spectroscopy, vol. 42, no. 8, pp. 1601-1605, 2011.

[28] G. Cassanas, G. Kister, E. Fabrègue, M. Morssli, and L. Bardet, "Raman spectra of glycolic acid, 1-lactic acid and d,l-lactic acid oligomers," Spectrochimica Acta Part A: Molecular Spectroscopy, vol. 49, no. 2, pp. 271-279, 1993.
[29] G. Kister, G. Cassanas, E. Fabrègue, and L. Bardet, "Vibrational analysis of ring-opening polymerizations of glycolide, L-lactide and D,L-lactide," European Polymer Journal, vol. 28, no. 10, pp. 1273-1277, 1992.

[30] F. R. Dollish, W. G. Fateley, and F. F. Bentley, Characteristic Raman Frequencies of Organic Compounds, John Wiley \& Sons, New York, NY, USA, 1974.

[31] G. Socrates, Infrared and Raman Characteristic Group Frequencies, John Wiley \& Sons, New York, NY, USA, 2001. 

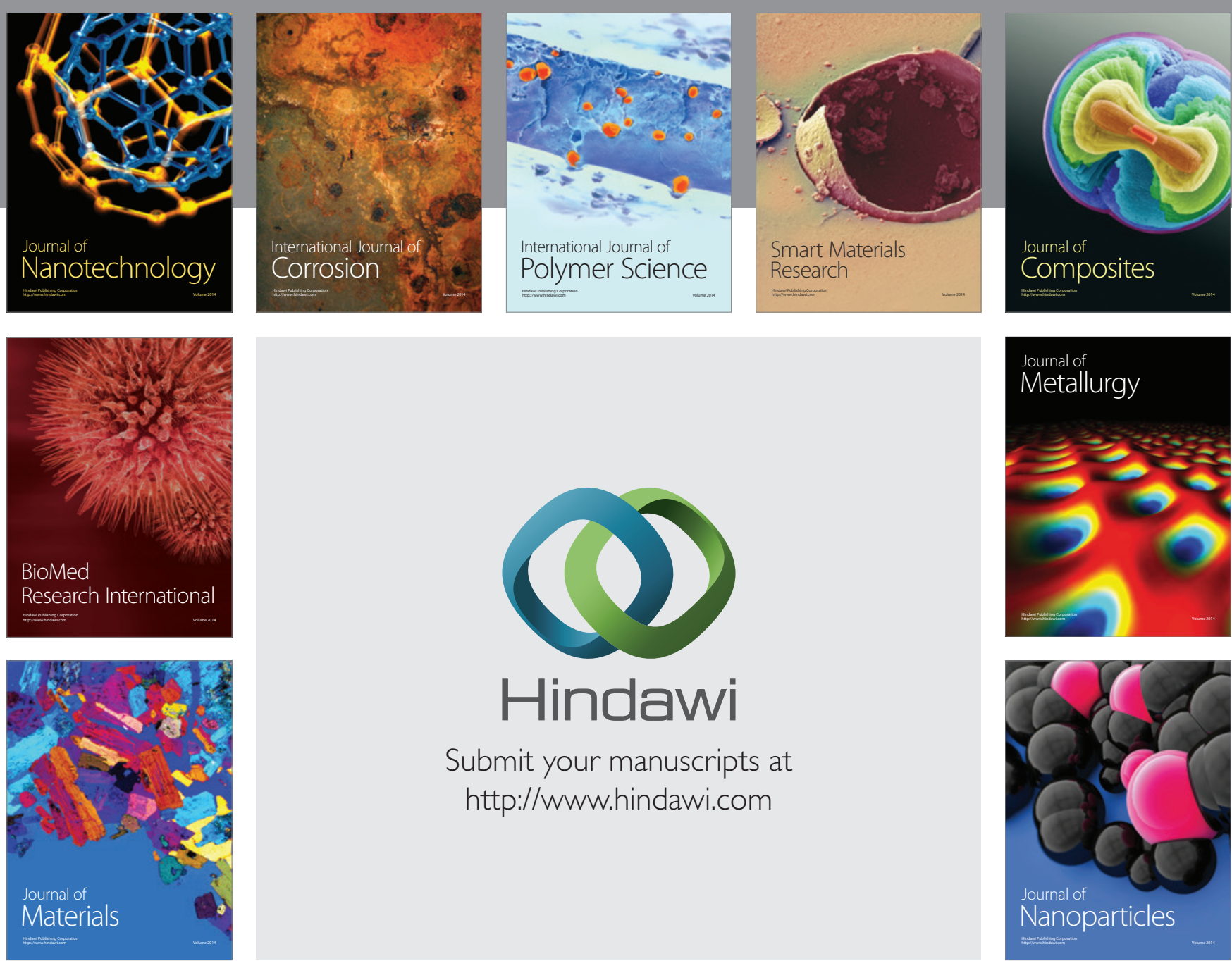

\section{Hindawi}

Submit your manuscripts at

http://www.hindawi.com

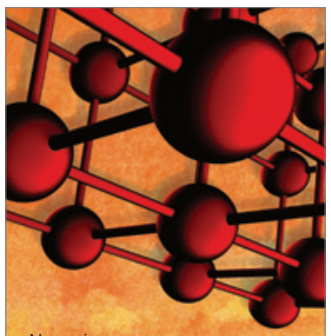

Materials Science and Engineering
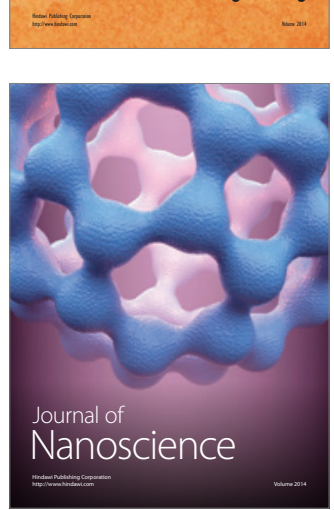
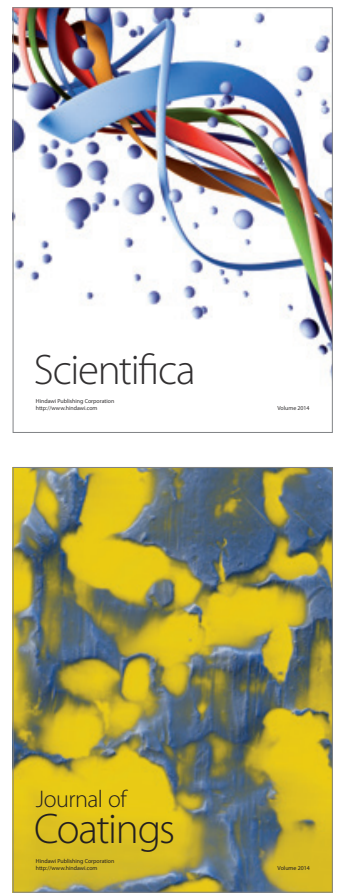
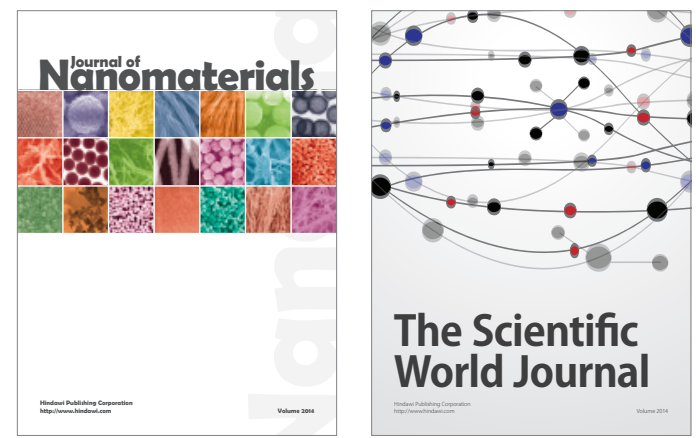

The Scientific World Journal
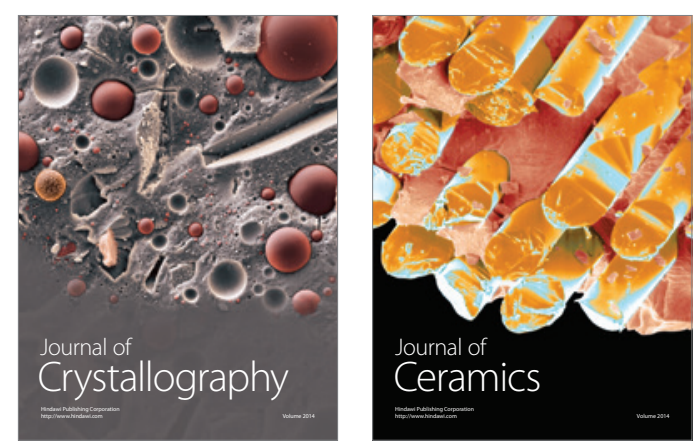
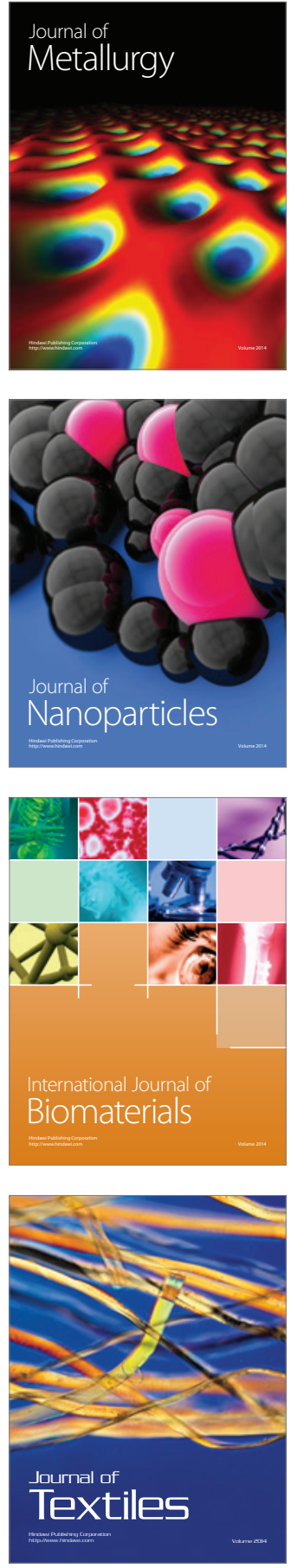